\title{
Erratum to: A mitochondrial division inhibitor, Mdivi-1, inhibits mitochondrial fragmentation and attenuates kainic acid-induced hippocampal cell death
}

Hwajin Kim ${ }^{1 *}$, Jong Youl Lee ${ }^{1}$, Keon Jae Park² ${ }^{2}$ Won-Ho Kim ${ }^{2}$ and Gu Seob Roh ${ }^{{ }^{*}}$

\section{Erratum to: BMC Neurosci (2016) 17:33 DOI 10.1186/s12868-016-0270-y}

In this version of this article that was originally published [1], there is incorrect funding information.

The funding information is currently:

This study was supported by a Grant of the Basic Science Research Program through the National Research Foundation (NRF) of Korea (Nos. 2014-0420 and 2015R1A5A2008833).

However, the number 2014-0420 is incorrect and should be 2014R1A1A1003211.

\section{Author details}

${ }^{1}$ Department of Anatomy and Convergence Medical Science, Institute of Health Sciences, Gyeongsang National University School of Medicine, 15, 816 Beon-gil, Jinju-daero, Jinju, Gyeongnam 660-751, Republic of Korea. ${ }^{2}$ Division of Metabolic Diseases, Center for Biomedical Sciences, Korea National Institute of Health, Osong, Republic of Korea.

The online version of the original article can be found under doi:10.1186/s12868-016-0270-y.

Received: 13 January 2017 Accepted: 13 January 2017

Published online: 23 January 2017

\section{Reference \\ 1. Kim H, Lee JY, Park KJ, Kim WH, Roh GS. A mitochondrial division inhibitor, Mdivi-1, inhibits mitochondrial fragmentation and attenuates kainic acid- induced hippocampal cell death. BMC Neurosci. 2016;17:33.}

\footnotetext{
*Correspondence: hwajin1@gmail.com; anaroh@gnu.ac.kr

1 Department of Anatomy and Convergence Medical Science, Institute of Health Sciences, Gyeongsang National University School of Medicine,

15, 816 Beon-gil, Jinju-daero, Jinju, Gyeongnam 660-751, Republic

of Korea

Full list of author information is available at the end of the article
} provided you give appropriate credit to the original author(s) and the source, provide a link to the Creative Commons license, and indicate if changes were made. The Creative Commons Public Domain Dedication waiver (http://creativecommons.org/ publicdomain/zero/1.0/) applies to the data made available in this article, unless otherwise stated. 